\title{
SPECIAL COMMUNICATION
}

\section{Complex regional pain syndrome of the foot and its management using spinal cord stimulation}

\section{El síndrome de dolor regional complejo del pie y su gestión mediante la estimulación de la médula espinal}

\author{
Paul Beeson ${ }^{1 *}$, Robert Ashford², Jon Raphael ${ }^{3}$ \\ 1. School of Health, The University of Northampton, Northampton, England. \\ 2. Faculty of Health, Birmingham City University, Birmingham. England. \\ 3. Department of Pain Management, Russells Hall Hospital, Dudley, England. \\ *Correspondence: Dr Paul Beeson (Senior Lecturer). School of Health. The University of Northampton. Park Campus, Boughton Green Road. \\ Northampton NN2 7AL. England. Tel: +44 (0)1604 892304. Email: paul.beeson@northampton.ac.uk
}

\section{Abstract}

Objective: This article discusses neuropathic foot pain with particular reference to complex regional pain syndrome. It provides recommendations for the clinical evaluation of complex regional pain syndrome and highlights the value of spinal cord stimulation in its management. The aim is to review neuropathic foot pain in complex regional pain syndrome and outline its management using spinal cord stimulation. It is important for Podiatrists managing such patients to have an understanding of this treatment modality.

Methods: A narrative literature review was undertaken using English language medical databases combining search strategies for complex regional pain syndrome and spinal cord stimulation.

Results: Spinal cord stimulation improves the subjective symptoms of the neuropathic foot pain of complex regional pain syndrome, enables objective functional improvement and reduces analgesic consumption.

Conclusion: Recent technical developments in spinal cord stimulation have led to improved stimulation patterns adapted to the patients' needs. Careful preoperative diagnosis, robust patient selection and frequent follow-up are vital for the success of this method.

Key Words: complex regional pain syndrome; spinal cord stimulation; Neuralgia; foot; management.

\section{Resumen}

Objetivos: Este artículo describe el dolor neuropático de los pies con especial referencia al síndrome de dolor regional complejo. Proporciona recomendaciones para la evaluación clínica del síndrome de dolor regional complejo y pone de relieve el valor de la estimulación de la médula espinal en su gestión. El objetivo es revisar dolor en el pie neuropático en el síndrome de dolor regional complejo y resumen de su gestión mediante la estimulación de la médula espinal.

Material y métodos: Una revisión de la literatura narrativa se llevó a cabo utilizando bases de datos médicas de idioma Inglés la combinación de estrategias de búsqueda para el síndrome de dolor regional complejo y estimulación de la médula espinal.

Resultados: Estimulación de la médula espinal mejora los síntomas subjetivos del dolor neuropático pies del síndrome de dolor regional complejo, permite la mejora funcional objetivo y reduce el consumo de analgésicos.

Conclusión: Los avances técnicos recientes en la estimulación de la médula espinal han dado lugar a patrones de estimulación mejoradas adaptaciones a las necesidades del paciente. diagnóstico preoperatorio cuidadosa, la selección de pacientes robusto y seguimiento frecuente son vitales para el éxito de este método. Es importante que los podólogos gestión de estos pacientes a tener una comprensión de esta modalidad de tratamiento.

Palabras Clave: Síndrome de dolor regional complejo; estimulación de la médula espinal; neuralgia; pie; administración

Received: 24 May 2016; Acept: 17 September 2016.

Conflicts of I nterest

The authors declare no potential conflicts of interest with respect to the research, authorship, and/or publication of this article.

Funding

The authors received no financial support for the research, authorship, and/or publication of this article. 


\section{Introduction}

Neuropathic pain constitutes a major portion of chronic pain and is an important, prevalent, and multifaceted problem. It has several components sensory, autonomic, motor and affective (emotional) (1); each dimension occurring in isolation or in varying combinations (1). This disorder arises from damage, or pathological change, in the peripheral or central nervous system (2). It is usually a chronic condition and can be difficult to treat because conventional analgesics may not provide effective pain relief. Neuropathic pain syndromes are multidimensional, with psychological and functional issues (3) and numerous causes exist which can affect the lower limb (Table 1). Overall the condition is a large cost burden on healthcare services and is frequently associated with considerably greater impairment of quality of life compared to other kinds of chronic pain (3). The article aims to review neuropathic foot pain in complex regional pain syndrome (CRPS) and outline its management using spinal cord stimulation (SCS).

\section{Definition of neuropathic pain}

In contrast to inflammatory or nociceptive pain (caused by actual tissue damage), neuropathic pain arises as a direct consequence of a lesion or disease process affecting the somatosensory system (4).

Peripheral and /or central nervous system can be affected (Table 1). Accordingly this can be peripheral or central neuropathic pain (depending on the site of lesion/dysfunction). As such, it represents a varying set of symptoms rather than a single entity (2). Somatosensory system damage can provoke a range of responses; an absence of sensation and pain is probably a more common response than new onset of pain. Sensitization of peripheral nerves with ectopic or spontaneous activity and hyper excitability in the modulatory pathways of the central nervous system are proposed mechanisms (5-7).

\section{Causes of neuropathic pain}

No universally accepted classification for neuropathic pain exists, however overlapping of several different disease processes may be responsible. Four broad classes of diseases are recognized based on aetiology and anatomy (5): focal and multifocal lesions of the peripheral nervous system, generalised polyneuropathies of peripheral nervous system, lesions in the central nervous system and complex neuropathic disorders (2) (Table 1).

Table 1: Lower limb neuropathic pain syndromes

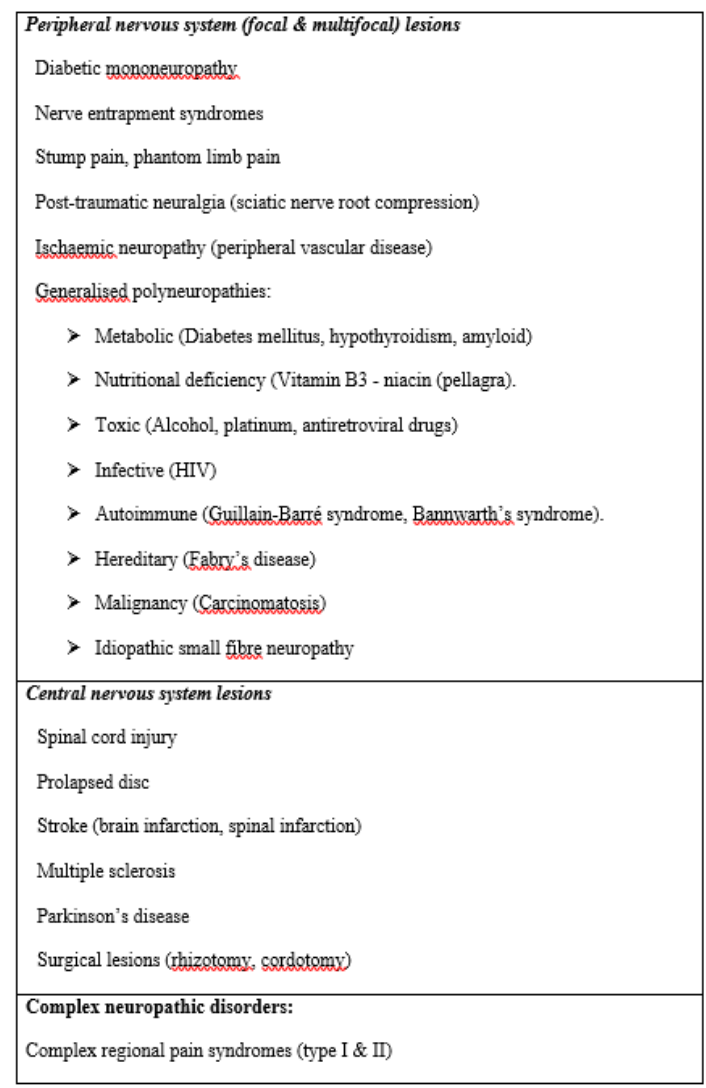

\section{Prevalence of neuropathic pain}

Estimates of neuropathic pain associated with specific aetiologies have been described (2). Researchers have reported age standardized incidence rates of 26.7 for painful diabetic neuropathy, and 0.8 for phantom limb pain (8). The prevalence of neuropathic pain rises with age and severity of the underlying condition $(9,10)$. 
Overall prevalence of neuropathic pain in the general population is more difficult to quantify due to the numerous underlying causes and the lack of standardized measurement methods (2). Chronic pain is defined as pain, which has presented for greater than three months duration (7). Epidemiological surveys suggest that 6-8\% of the general population report chronic pain with neuropathic characteristics $(11,12)$. Neuropathic back pain with radiating pain to the leg, and posttraumatic neuropathic pain (accidental or surgical injury) are probably the most common causes (2). Sixty to eighty patients out of every 1000 registered with a general practitioner will have symptoms of neuropathic pain; in half of these patients, pain will require medication and regular support (13).

\section{Clinical presentation of neuropathic pain}

The symptoms of neuropathic pain are often different than the traditional pain symptoms patients commonly experience. Painful symptoms often arise in an area of altered sensation (numbness or hyper excitability) and these are the hallmark of neuropathic pain. The cardinal symptoms of spontaneous pain and abnormal response to stimuli are common (2). The symptoms of neuropathic pain are summarized in Table 2. These are in contrast to nociceptive pain symptoms, which are usually described as sharp, aching, and/or throbbing pain (14). The features of neuropathic pain may be evident within days of nerve damage or can take months to develop. Sometimes, a minor insult to an area previously injured that had healed without a problem can trigger onset of neuropathic pain (2).

Table 2: Neuropathic pain symptoms

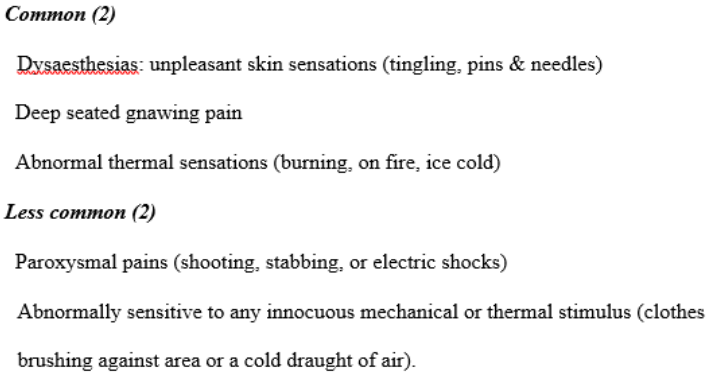

\section{Materials and Methods}

The following criteria were used to search the literature:

1. English language human studies.

2. A narrative review of literature on use of spinal cord stimulation in complex regional pain syndrome published between 1993 and 2016.

3. Electronic databases: MEDLINE, PubMed, BioMed Central, Cochrane library, CINAHL, Highwire, AMED, Ovid, EMBASE, Science direct, BMJ clinical evidence, Science citation index, The Lancet.com, Scirus.com, Index to thesis, Controlledtrials.com UK.

4. Medical subject heading terms used alone or in combination: Neuropathic pain, foot, lower limb, spinal cord stimulation, complex regional pain syndrome.

5. Search limited to: peer-reviewed journals, systematic reviews/ meta-analyses, Randomized Controlled Trials, cohort studies, case control studies.

6. Systematic reviews specific to CRPS and SCS were accessed to ensure high quality data and limit bias.

7. Research papers were chosen based upon evaluation of neuropathic lower limb pain, complex regional pain syndrome and spinal cord stimulation. 


\section{Results}

Different methodological approaches were used to examine CRPS. Few included appropriate controls and sufficient cohort size to enable suitable statistical analysis with appropriate power calculation (15, 16). This made comparison and interpretation of CRPS studies difficult. Varied standardized criteria were used to confirm CRPS diagnosis but not all were evidence-based $(15,17)$. This has led to over diagnosis and often excessive pharmacotherapy (17). Where conservative treatment proved unsuccessful in controlling pain symptoms SCS was considered.

Studies concurred that SCS is an effective management of the neuropathic foot pain of CRPS (18-20). SCS has been found to improve subjective symptoms, enable objective functional improvement and reduce the level of analgesic consumption (21, 22). Furthermore recent technical developments in SCS have led to improved stimulation patterns adapted to individual patients' needs (23).

\section{Discussion}

\section{Complex regional pain síndrome}

CRPS is a term devised by the International Association for the Study of Pain ${ }^{[14]}$. It is referring to a variety of disorders characterized by spontaneous pain, which is disproportionate to the provoking event and accompanied by a multitude of autonomic and motor disturbances in variable combinations (14). As such it probably has a multimodal aetiology (14).
CRPS is a debilitating and painful condition, predominately affecting distal limbs after trauma. Researchers have reported a 4:1 female to male ratio with a higher incidence rate in Caucasians (24). The average age of onset of 40 year-of-age has been reported (14). It is defined as a regional neuropathic pain disorder arising in the context of a fracture, soft tissue injury or surgical trauma (14, $25)$, although in about $10 \%$ of cases no precipitating event can be identified $(14,25,26)$.

CRPS usually affects one limb, but in $7 \%$ of cases later spreads to involve additional limbs (27).

The incidence of upper limb CRPS is twice as common as lower limb (28). The clinical phenotype of CRPS has been better defined over the last few decades: diagnostic criteria such as Budapest or Veldman capture these essential clinical features $(29,30,31)$ but no diagnostic tests are available (14). It is noted that, without limb signs, a diagnosis of CRPS according to the Budapest criteria can often not be made $(26,31)$.

CRPS is primarily associated with sensory, motor, autonomic, skin and bone abnormalities (32). Clinical features of spontaneous pain, oedema, hyperalgesia, temperature or sudomotor changes, motor function abnormality, and autonomic changes (Table 3) are the hallmark of CRPS (34).

The factors necessary to evaluate a patient with CRPS are summarized in Table 3. 
Table 3. Considerations when evaluating Complex Regional Pain Syndrome

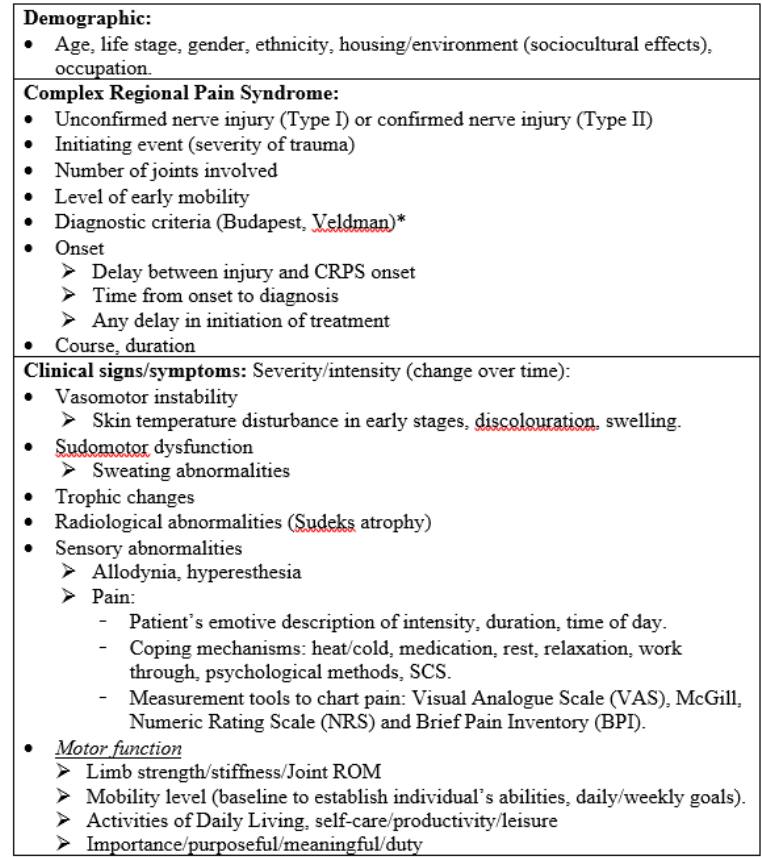

*Footnote:

The Budapest (22) or Veldman (33) criteria may be applied to help confirm CRPS diagnosis.

CRPS is often misdiagnosed as it can mimic a large number of similar conditions; hence affected patients typically experience a delay in diagnosis and commencement of appropriate management. Most experts believe that CRPS is multifactorial in nature and pathophysiology $(14,28)$. These include inflammation, autoimmune responses, abnormal cytokine production, sympathetic sensory disorders, altered blood flow and central cortical reorganization (15). Due to the multifactorial pathophysiology, CRPS can differ in severity and duration between patients, and can even vary with time in the same patient (16). Incidence and prevalence studies of CRPS show that most cases are mild and individuals recover gradually with time. In severe cases, individuals may not recover and may suffer long-term disability $(26,17)$.
CRPS is believed to be caused by damage to, or malfunction of, the peripheral and/or central nervous systems (28). Onset of symptoms can occur within one month of trauma or immobilization of the limb and the pain experienced is out of proportion in relation to the trauma (26). CRPS is characterized by prolonged (normally $>6$ months) or excessive pain and mild to dramatic changes in skin colour, temperature, and/or swelling in the affected area (35).

Two forms of CRPS exist (CRPS-1 and CRPS-II), with the same symptoms and treatments. CRPS-II (previously called causalgia) is the term used for patients with confirmed nerve injuries (17). Individuals without confirmed nerve injuries are classified as having CRPS-I (previously called reflex sympathetic dystrophy). Some research has identified evidence of nerve injury in CRPS-I, so the validity of the two different forms is being investigated (35).

Scant information is available regarding the types of patients who develop CRPS in the lower extremity (36, 37). A retrospective study examined 64 patients (predominantly white, middle-aged women) with lower extremity CRPSI (38). The most common precipitating injuries observed were blunt foot trauma (with or without fracture) or ankle sprain. The most common inciting surgical events were hallux valgus, tarsal tunnel release and heel surgery (38). In lower extremity CRPS the dominant cause is trauma (73\%) with elective foot surgery accounting for the remaining cases (27\%) (16). The most common type of trauma was fracture $(45 \%)$ whereas neurectomy was the most common type of elective foot surgery. Research reveals middleage females with a history of anxiety or depression have a greater risk of developing CRPS after foot and ankle surgery (29). A recent study identified novel risk factors relating to deep-tissue ischaemia following surgical repair of peripheral fractures, thus providing new insights into one of the triggers of CRPS (39). 
Findings about CRPS are conflicting. This may be due to the complexity of and difficulty in researching the condition. Different methodologies such as the variable use of standardized criteria to confirm diagnosis make comparison of study findings difficult to interpret.

\section{Management of CRPS}

Recent and significant advances across medical disciplines have improved the general understanding of CRPS (28). Current evidence indicates that CRPS is a disorder of multifactorial origin and of complex pathophysiology. Hence carefully selected multimodal management using a biopsychosocial approach is indicated.

Pharmacological and non-pharmacological treatment is carefully tailored to individual needs depending on the stage and severity of the condition (28). Treatment of CRPS remains controversial and the literature reports various methods (Table 4), however, the goals are similar; pain relief, decrease in morbidity, and restoration of functional status (34).

Table 4: Management of Complex Regional Pain Syndrome

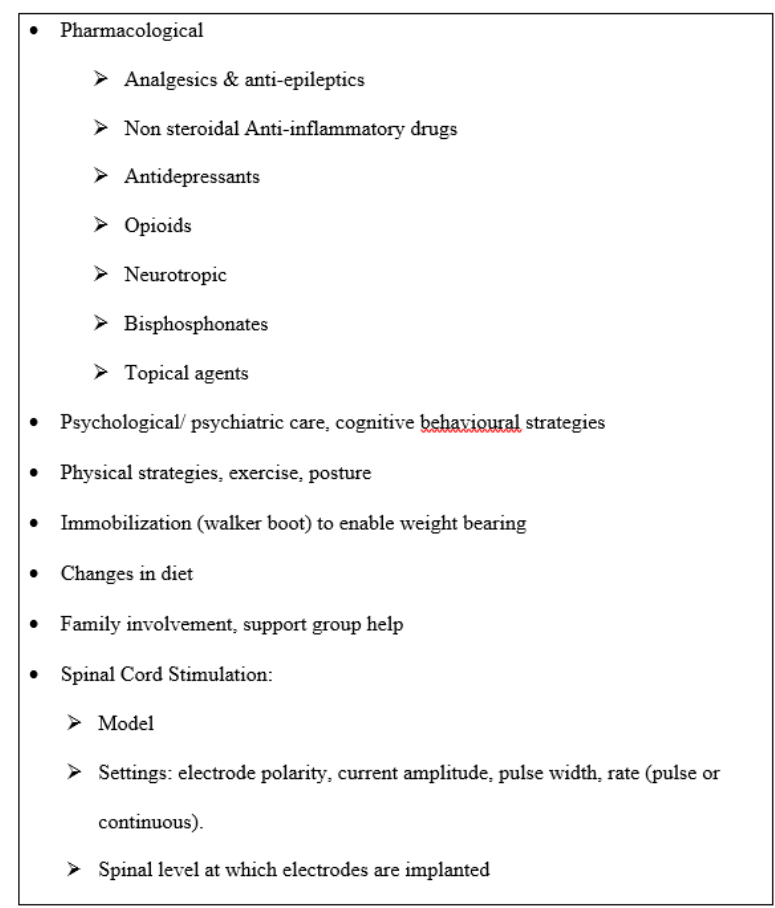

Neuropathic pain is an inherently biopsychosocial problem with an important psychological component. It can potentially influence every human activity and experience and is therefore very personal in the way in which it is perceived. Since research and treatment activities are also patterns of human behaviour, pain is a challenging problem from a psychological point-of-view. Consequently its management model needs to be complex enough to meet the notions of health and behavior change.

The dominant psychological approach to chronic pain is cognitive behavioural therapy ${ }^{[40]}$, a psychotherapeutic approach combining cognitive and behaviour therapy. It focuses on how a patient thinks about things going on in their life - their thoughts, images, beliefs and attitudes (cognitive processes) and how these impact on the way they behave and deal with emotional problems ${ }^{[40]}$. A number of psychosocial issues are known to influence the care of CRPS (Table 5).

Table 5: Psychosocial issues influencing care of Complex Regional Pain Syndrome

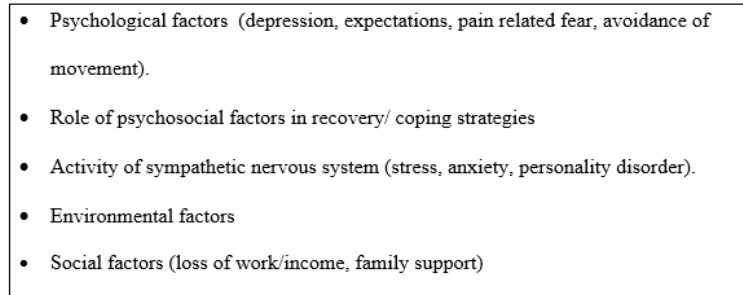

In cases of CRPS where conservative treatments are unsuccessful in controlling pain symptoms SCS may need to be considered. 


\section{The application of spinal cord stimulation}

Spinal cord stimulation is generally reserved for CRPS which is refractory to conventional conservative management. It is a relatively safe procedure and reversible with implant removal. The pain relieving effect of SCS as a treatment of neuropathic pain, pain due to peripheral ischemia and angina pectoris is well recognized (18-20, 41).

Recent technical advancement of SCS enables stimulation patterns to be adjusted according to the patient's needs, thus increasing stimulation efficiency. The neuromodulatory technique of SCS has evolved as a direct clinical application of the gate-control theory, the general conceptualization of which still provides the framework in explaining its mode of action (3).

According to the theory, the proposed gating mechanisms activated by SCS would imply that both acute and chronic pain of a nociceptive nature could be suppressed (3). This is an inconsistency because SCS is preferentially, or perhaps exclusively, effective for neuropathic pain management $(3,41)$.

The National Institute for Clinical Excellence has shown SCS to be cost effective in the managing CRPS (42). A growing body of evidence supports the benefits of SCS in managing neuropathic pain (3, 21, 22, 43-45). Studies of SCS demonstrate greater efficacy in neuropathic as opposed to nociceptive pain syndromes; however, the neurobiology for this is poorly understood (3).

Successful management with SCS depends on a robust multidisciplinary approach to patient selection and management (3). The psychological profile of patients chosen for SCS must be considered (3).

The waiting time from development of chronic pain syndrome to initiation of SCS can influence treatment efficacy. SCS efficacy is inversely proportional to the time interval between development of chronic pain and time of SCS implantation (44).

\section{Explanation of spinal cord stimulation}

Stimulating electrodes are placed through a needle into the spine near the spinal cord and activated to provide a mapped paraesthesia in the painful area. In the case of lower limb pain, the usual electrode position is Thoracic10-12 vertebral level. A twostep procedure is undertaken with a test phase before implantation of the impulse generator (IPG). Typically the electrode is placed temporarily for several days to assess whether stimulation will be helpful (stage 1).

Efficacy measures include: subjective symptom improvement, objective reduced analgesic consumption, and objective improvement in function. If successful ( $>50 \%$ pain reduction), either a laminotomy is undertaken (stage 2) to insert a surgical paddle or the percutaneous trialed leads are internalized. The IPG is connected to the leads and implanted under the skin on the abdomen, buttock or side of the chest (Figure 1) (3). Once implanted, the stimulator can be turned on and off, and adjusted (programmed) using an external controller. Electrode polarity (anode, cathode), current amplitude, pulse width, and rate can be regulated to achieve optimum analgesia.

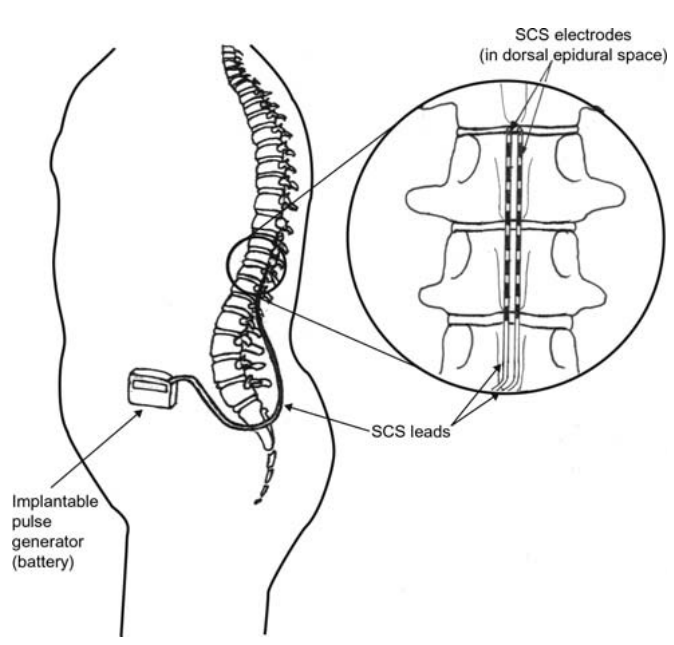

Figure 1. Schematic of implanted Spinal Cord Stimulation (Raphael et al, 2009). With permission. 
Re-programing of the IPG is often needed one or more times. The patient can determine over time which stimulation pattern (intermittent or continuous) is most suitable. The SCS creates paraesthesia over the area of pain and can give several hours of pain relief after cessation of the stimulation. Position-adaptive IPG devices now detect whether the patient is lying down or standing so there is no longer any need for the patient to adjust stimulation intensity after changing their position.

\section{Analgesic mechanisms}

A number of neurotransmitters change with SCS. The anti-nociceptive effects of SCS are due to modulation of gamma amino-butyric acid release in the dorsal horn, which may modulate pain by controlling the release of excitatory amino acids (asparte \& glutamate) (3). A similar model lends support to the modulatory role of SCS upon adenosine in the dorsal horn. Other mediators through which some analgesic effects of SCS may act include serotonin and substance P (46).

\section{Indications for use}

Numerous indications exist for the use of SCS for neuropathic lower limb pain (Table 6.). Spinal cord stimulation is contraindicated in the presence of marked psychological difficulties (major depression, anxiety, personality disorder, psychosis or poor coping strategy), coagulation abnormalities (including anticoagulant therapy), demand pacemaker, implanted defibrillator, systemic/ local infection and immunosuppression $(3,23)$.
Table 6. Lower limb indications of Spinal Cord Stimulation

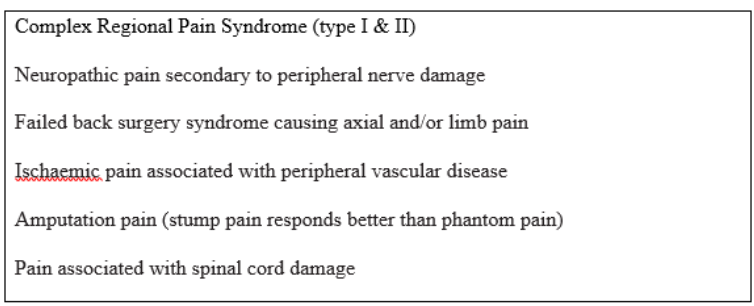

\section{Limitations/ risk of bias}

The review was not without limitations. Papers were confined to English language only as translation services were unavailable. The literature was reviewed by one researcher (PB), although all authors were involved in appraising the overall findings and their relevance.

\section{Conclusions}

This paper outlines the value of using a SCS for managing the neuropathic foot pain of CRPS, where standard treatment modalities have failed to control symptoms. Spinal cord stimulation has been shown to be a clinically and cost-effective therapy in the management of patients with CRPS $(20,47,48)$. Technical advancements of SCS have led to improved stimulation patterns adapted to the patients' needs. Careful preoperative diagnosis, robust patient selection and frequent follow-up are vital for the success of this method. 


\section{References}

1. O’Hara P. Pain Management for Health Professional, $1^{\text {st }}$ ed. London Chapman \& Hall; 1996, p.102-6.

2. Freynhagen R, Bennett MI. Diagnosis and management of neuropathic pain. BMJ 2009; 339:391-395.

3. Raphael J, Mutagi HS, Kapur S. Spinal cord stimulation and its anaesthetic implication. CEACCP 2009; 9: 78-81.

4. Treede RD, Jensen TS, Campbell JN et al. Neuropathic pain: redefinition and a grading system for clinical and research purposes. Neurology. 2008;70:1630-5.

5. Baron R. Mechanisms of disease: neuropathic pain: a clinical perspective. Nat Clin Pract Neurol 2006;2:95-106.

6. Scholz J, Woolf CJ. The neuropathic pain triad: neurons, immune cells 3 and glia. Nat. Neurosci 2007;10:1361-8.

7. Turk DC, Okifuji A. Pain terms and taxonomies of pain In: Loeser JD, Butler SH, Chapman CR, et al, Editors. Bonica's Management of Pain

3rd ed, Baltimore MD Lippincott Williams \& Wilkins; 2001, p.17-25.

8. Hall GC, Carroll D, McQuay H. Primary care incidence and treatment of four neuropathic pain conditions: a descriptive study, 2002-2005. BMC Fam Pract 2008; 9:26.

9. Freynhagen R, Baron R, Gockel U et al. Pain DETECT: a new screening questionnaire to identify neuropathic components in patients with back pain. Curr Med Res Opin 2006;22:1911-20.

10. Gustorff B, Dorner T, Likar R, et al. Prevalence of selfreported neuropathic pain and impact on quality of life: a prospective representative survey. Acta Anaesthesiol Scand 2008;52:132-6.

11. Torrance N, Smith BH, Bennett MI. The epidemiology of chronic pain of predominantly neuropathic origin. Results from a general population study. J Pain 2006;7:281-9.

12. Bouhassira D, Lanteri-Minet M, Attal N et al. Prevalence of chronic pain with neuropathic characteristics in the general population. Pain 2008;136:380-7.

13. McDermott AM, Toelle TR, Rowbotham DJ, et al. The burden of neuropathic pain: results from a cross-sectional survey. Eur J Pain. 2006;10:127-135.

14. Fukushima FB, Bezerra DM, Villas Boas PJD et al. Complex Regional Pain Syndrome, BMJ 2014;349:32-5.

15. Borchers AT, Gershwin ME. Complex regional pain syndrome: A comprehensive and critical review, Autoimmunity Reviews 2014; 13:242-265.

16. Shah A, Kirchner SJ. Complex regional Pain syndrome, Foot and Ankle Clinics 2011;16:351-366.

17. Bean DJ, Johnson MH, Kydd RR. The outcome of Complex Regional Pain Syndrome Type1: A systematic review. Journal of Pain 2014;15:677-690.

18. Kemler MA, Barendse GA, van Kleef $M$ et al. Spinal cord stimulation in patients with chronic reflex sympathetic dystrophy. N Engl J Med 2000;24:618-24.
19. Kemler MA, DeVet HCW, Barendse GAM et al. The effect of spinal cord stimulation in patients with chronic reflex sympathetic dystrophy: two year follow-up of the randomized controlled trial. Ann Neurol 2004;55:13-18.

20. Kemler MA, de Vet H, Barendse G, van den Wildenberg $F$ et al. Spinal cord stimulation for chronic reflex sympathetic dystrophy: five year follow-up. N Eng J Med 2006;354:394-6.

21. Kumar K, Taylor RS, L. Jacques, et al. The effects of spinal cord stimulation in neuropathic pain are sustained: a 24-month follow-up of the prospective randomized controlled multicenter trial of the effectiveness of spinal cord stimulation. Neurosurgery 2008;63:762-770.

22. Mailis-Gagnon A, Furlan AD, Sandoval JA et al. Spinal cord stimulation for chronic pain, Cochrane Database of Systematic Reviews 2004, CD003783.

23. Wolter T. Spinal cord stimulation for neuropathic pain: current perspectives. J Pain Res 2014;4:651-663

24. Sandroni P, Benrud-Larson LM, McClelland RL et al. Complex Regional Pain Syndrome Type I: Incidence and prevalence in Olmsted County, a population-based study. Pain 2003;103:199-207.

25. Kishner S, Rothaermel JB, Munshi, BS et al. Complex Regional Pain Syndrome, Turkish J Phys Med \& Rehab 2011;57: 156-164.

26. Royal College Physicians. Complex Regional Pain Syndrome in adults: UK guidelines for diagnosis, referral and management in primary and secondary care. London. 2012.

27. Van Rijn MA, Marinus J, Putter $\mathrm{H}$ et al. Spreading of Complex Regional Pain Syndrome: not a random process. J Neural Transm 2011;118:1301- 9.

28. Marinus J, Moseley LG, Birklein F et al. Clinical features and pathophysiology of Complex Regional Pain Syndrome. Lancet Neurology 2011;10:637-648.

29. Rewhorn MJ, Leung AH, Gillespie A et al. Incidence of Complex Regional Pain Syndrome after foot and ankle surgery. J Foot Ankle Surg 2014;53:256-8.

30. Littlejohn G. Complex regional pain syndrome. Perioperative triggers. Rheumatology 2014;53:1157-8.

31. Harden RN, Bruehl S, Perez RS et al. Validation of proposed diagnostic criteria (The 'Budapest Criteria') for Complex Regional Pain Syndrome. Pain 2010;150: 268274.

32. Turner-Stokes L, Goebel A. Complex Regional Pain Syndrome in adults: concise guidance. Clinical Medicine 2011;11:596-600.

33. Veldman PH, Reyman HM, Arntz IE et al. Signs and symptoms of réflex sympathetic dystrophy: prospective study of 829 patients. Lancet 1999;342:1012-1016. 
34. McBride A, Atkins R. Complex Regional Pain Syndrome, Current Orthopaedics 2005;19155-165.

35. National Institute of Neurological Disorders and Stroke 2014: Accessed at: http://www.ninds.nih.gov/disorders/reflex_sympathetic_d ystrophy/detail_reflex_sympathetic_dystrophy.htm

36. Allen G, Galer BS, Schwartz S. Epidemiology of complex regional pain syndrome: a retrospective chart review of 134 patients. Pain 1999;80:539-544.

37. Bacchini M, Vaienti E, Soncini G. Post-traumatic reflex sympathetic dystrophy in the foot and ankle: a study of 32 cases, Chir Organi Mov 1999;84:189-196.

38. Harris J, Fallat L, Schwartz S. Characteristic Trends of Lower-Extremity Complex Regional Pain Syndrome. J Foot \& Ankle Surg 2004;43:296-301.

39. Masahiko S, Hideo Y, Kanji U et al. Perioperative factors affecting the occurrence of acute Complex Regional Pain Syndrome following limb bone fracture surgery: data from the Japanese Diagnosis Procedure Combination database, Rheumatology 2014;53:11861193.

40. McCracken LM, Morley S. The Psychological Flexibility Model: A Basis for Integration and Progress in Psychological Approaches to Chronic Pain Management. The Journal of Pain 2014;15:221-234.

41. Myerson BA, Linderoth B. Mechanisms of spinal cord stimulation in neuropathic pain. Neurological Research 2000;22:285-292.

42. National Institute for Health and Clinical Excellence. Spinal Cord Stimulation for Chronic Pain of Neuropathic or Ischaemic Origin. London. 2008.

43. Kavar B, Rosenfeld JV, Hutchinson A. The efficacy of spinal cord stimulation for chronic pain, J Clin Neuroscience 2000;7:409-13.

44. Kumar K, Taylor R, Jacques L et al. Spinal cord stimulation versus conventional medical management for neuropathic pain: a multi-centre randomized controlled trial in patients with failed back surgery syndrome. Pain 2007;132: 179-188.

45. Spinal cord stimulation for the management of pain: recommendations for best clinical practice, British Pain Society; 2008.

46. Elliott JA, Norregaard TV. Neuromodulation for pain. In: Warfield CA, Bajwa ZW, Editors. Principles \& Practice of Pain Medicine, 2nd Edn. New York McGraw-Hill; 2004: stimulation 740-6.

47. Taylor RS, Van Buyten JP, Buchser E. Spinal cord stimulation for complex regional pain syndrome: a systematic review of the literature of the clinical and costeffectiveness literature and clinical assessment of prognostic factors. Eur J Pod 2006;10:91.
48. Hylands-White $\mathrm{N}$, Duarte RV, Beeson P. Electroencephalographic evoked pain response is suppressed by spinal cord stimulation in complex regional pain syndrome: a case report. J Clin Monit Comput 2015; $10: 1-4$. 